\title{
Sensualismo e Antimaterialismo em Rousseau
}

\section{Gustavo Cunha Bezerra ${ }^{1}$}

\begin{abstract}
RESUMO: Procuraremos analisar, neste artigo, o duplo movimento do pensamento rousseauniano, que, se, por um lado, se apresenta acentuadamente sensualista, principalmente nos primeiros livros do Emílio, por outro lado, encontra o limite desse sensualismo nas consequências extremas do materialismo de Diderot e Helvétius. Apontaremos aqui a proximidade de Rousseau com o pensamento que deriva da estátua hipotética de Condillac, mas que rejeita completamente a afirmaçáo de que "julgar é sentir", proclamada por Helvétius. Para o autor da Profissáo de fé do Vigário saboiano, o julgamento não pode ser reduzido à passividade das sensaçôes, mas é resultado da intervenção ativa do $e u$, uma vontade livre e inteligente.
\end{abstract}

PALAVRAS-CHAVE: Materialismo. Rousseau. Sensualismo.

$\mathrm{Na}$ Profissão de fé do Vigário saboiano, Rousseau constrói um sistema ${ }^{2}$ filosófico que defende a existência da substância imaterial, a liberdade do homem, a ordem universal estabelecida por Deus e a religiáo natural. Analisaremos, neste artigo, a relação entre o sensualismo, presente principalmente nos primeiros livros do Emílio, e o problema que envolve a discussão sobre a substância imaterial.

A reflexão filosófica sobre a atividade do espírito é desenvolvida ao longo da primeira parte da Profissáo de fé, a parte que Rousseau, quando se defende dos ataques de Beaumont, classifica como "a mais importante" e

\footnotetext{
${ }^{1}$ Professor Substituto do Instituto Federal de Educação, Ciência e Tecnologia do Rio Grande do Norte (IFRN), Campus Natal Cidade-Alta. E-mail: gcbezerra@hotmail.com.

http://dx.doi.org/10.1590/S0101-31732016000300004

${ }^{2}$ Seria importante comentar brevemente sobre a presença de um sistema filosófico, no pensamento rousseauniano, pois não é raro que suas obras sejam qualificadas como paradoxais. Quando se tem em vista a Profissão de fé, torna-se mais fácil perceber a preocupação de Rousseau em pensar sistematicamente. Ainda que, no início mesmo desse texto, o Vigário critique os sistemas filosóficos e afirme nâo ter " $[\ldots]$ nenhum sistema a sustentar" ( $O C$ IV, p. 582), seu pensamento será apresentado sob a forma de um sistema, tal como Rousseau aprendeu com Descartes, Locke e Condillac. As ideias do padre saboiano são expostas através de um discurso coerente que, nas palavras de Gouhier (2005, p. 85), se submete "[...] à obrigaçáo de explicar, de provar, de apresentar as ideias em certa ordem". Outro importante comentador, Pierre Burgelin (1973, p. 7), também aponta esse esforço "desagradável" do genebrino em sistematizar seu pensamento. Algo já iniciado na Carta a Voltaire, de 1756, na Peça alegórica sobre a revelação e nas Cartas morais.
} 
que tem como objetivo "[...] combater o materialismo" e "[...] estabelecer a existência de Deus e da religião natural” (OC IV, p. 996) ${ }^{3}$.

Antes de compreender esse "combate ao materialismo", é importante, entretanto, destacar que Rousseau é herdeiro das teorias sensualistas do século XVIII, sobretudo em relação à teoria de Condillac, construída a partir da hipótese da estátua descrita no Tratado das Sensaçóes.

\section{O SENSUALISMO DE ROUSSEAU E SUAS ORIGENS}

A identidade da estátua imaginada por Condillac restringe-se ao conjunto das experiências sensoriais, tanto as do presente, quanto aquelas conservadas pela memória. Quando a estátua possui apenas o olfato, por exemplo, e lhe é apresentada uma rosa, a sua existência se confunde com o odor da rosa: "[...] ela será apenas o odor mesmo dessa flor" (CONDILLAC, 1984, p.15) ${ }^{4}$. A aquisição da memória e dos outros sentidos permitirá que a estátua faça comparaçóes, que ela deseje aquilo que propicia prazer e repulse o que causa dor. É importante destacar que todas as transformaçôes sofridas pela estátua têm como única fonte as sensaçóes. Veremos, mais adiante, que essa proposição se torna inaceitável para o Vigário; apesar de reconhecido discípulo de Condillac, Rousseau rejeitará fortemente o sensualismo extremo do autor do Tratado das sensaçóes.

Em um primeiro momento, porém, o autor do Emílio parece não se inquietar com a tese da sensaçấo transformada de Condillac, na qual a atividade do espírito é reduzida à passividade das sensações. Nas Cartas Morais, como indica Schøsler, Rousseau faz referência ao Tratado das Sensações, "[...] mas não faz nenhuma menção à teoria 'passivista' do julgamento humano." (SCHØSLER, 1978, 65). O espanto de Rousseau com a redução do julgamento à simples

\footnotetext{
${ }^{3}$ As referências às obras de Rousseau remetem às Oeuvres completes, Bibliothèque de la Pléiade, 5 vols, 1959-1995. Nas citaçóes indico o número do volume e a página. As traduçôes para o português são de minha autoria.

${ }^{4}$ Tendo em vista a escassez de estudos brasileiros sobre Condillac, importa mencionar a existência da tradução do Tratado das Sensaçóes para o português, publicada pela Editora da UNICAMP em 1993. A tradução é de autoria de Denise Bottmann e é enriquecida com uma introdução ao texto de Condillac realizada por Luiz Roberto Monzani.

${ }^{5}$ Condillac, nas palavras de Schøsler, "identificando, por suas definiçôes, cada uma das operaçốes àquela que a precede e, dessa forma, todas à sensaçấo, ele declara que "o julgamento, a reflexão, os desejos, as paixóes etc, não são senão a própria sensaçăo que se transforma diferentemente”." (SCHØSLER, 1978, 64)
} 
sensação ocorrerá com a leitura do De l'Esprit, de Helvétius ${ }^{6}$, livro que procura defender, antes de tudo, a ideia de que toda a atividade do espírito, inclusive o julgamento, provém das sensações. A sentença "julgar é sentir" (HELVÉTIUS, 1988, p.24), formulada pelo autor logo no primeiro capítulo do De l'Esprit, é o ponto de partida para o materialismo de Helvétius.

Peter Jimack (1960) lembra a observação feita por Masson de que boa parte do que foi adicionado à primeira versão da Profissáa de fé se destina, principalmente, a refutar o livro de Helvétius. Com esse intuito, o Vigário saboiano procura demonstrar que o julgamento é uma força ativa que não pode ser reduzida à sensibilidade física, ou seja, o ato de comparar não pode ser visto como algo produzido "[...] a partir das modificaçôes da sensibilidade e de sua inscrição na memória." (CHARRAK, 2009, p.784). Todavia, como observa Jimack, "[...] se Rousseau experimenta essa necessidade de inserir no manuscrito B uma refutação da doutrina da passividade total do espírito, é que [...] sua concepção da gênese das ideias é completamente sensualista." (1960, p. 320).

De fato, nos dois primeiros livros do Emílio, a discussão sobre o desenvolvimento da criança é fortemente influenciada pela estátua de Condillac (cf. SCHØSLER, 1978). Uma criança que nascesse com o físico de um adulto, imagina Rousseau, "[...] seria um perfeito imbecil, um autômato, uma estátua imóvel e quase insensível” (OC IV, p.280), pois lhe faltaria o acúmulo das experiências sensoriais necessárias para seu desenvolvimento.

Por outro lado, na visão de Jimack (1960), essa suposição do homemcriança parece estar relacionada, antes, com uma semelhante hipótese elaborada por Buffon. Jimack se refere à passagem presente no Histoire naturelle de l'homme, em que Buffon imagina um homem no qual o corpo e os órgãos estariam perfeitamente formados, mas "[...] que tudo se apresentaria novo para ele.” (BUFFON apud JIMACK, 1960, p.328). No Traité des animaux, Condillac discorda da capacidade que Buffon atribui a esse homem, o qual,

\footnotetext{
${ }^{6}$ Schøsler (1978) observa, seguindo os estudos de Masson (da Édition critique de la Profession de foi, Paris, 1914), que a terceira carta das Cartas Morais foi escrita no inverno de 1757-58, enquanto a leitura do De l'Esprit ocorreu no outono de 1758.

${ }^{7}$ Sobre a abreviação dos manuscritos do Emílio, Masson (1914, p. C) faz a seguinte indicação: "F, Manuscrito de M. Léopold Favre; B, "Brouillon" do Palais-Bourbon; M, Cópia enviada a Moultou; I, Cópia destinada à Impressão". Segundo Jimack, o manuscrito B teria substituído o Manuscrito Favre, considerado a primeira redação do Emílio. "Depois da redação de B, afirma Jimack, Rousseau abandonou F, que náo tinha mais nenhuma utilidade; ainda que B náo seja o manuscrito definitivo do Emílio, sua redação terminou apenas quando Rousseau a copiou" (JIMACK, 1960, p. 28).
} 
no momento em que abrisse os olhos pela primeira vez, já seria capaz de ver "[...] a luz, a abóboda celeste, a vegetação da terra etc." (CONDILLAC, 1987, p.458). "Como seus olhos aprenderam a distinguir todos esses objetos?", questiona Condillac (1987, p.458). Esse homem não conseguiria ver, não teria consciência dos seus órgáos sensoriais, nem mesmo de que possui um corpo, ele precisaria ainda aprender a regular seus movimentos.

Como demonstra Jimack (1960), Rousseau segue de perto a crítica de Condillac a Buffon, quando expóe sua hipótese do homem-criança, o qual "[...] não veria nada, não escutaria nada, não conheceria ninguém, não saberia girar seus olhos na direção daquilo que ele teria necessidade de ver" (OC IV, p.280). Esse homem-criança, para Rousseau, também não reconheceria a existência de seus próprios órgãos sensoriais:

[...] as cores não estariam nos seus olhos, os sons não estariam nas suas orelhas, os corpos que ele tocaria náo estariam sobre o seu, ele não saberia mesmo que tem um: o contato de suas mãos estaria no seu cérebro; todas as sensaçóes se reuniriam em um só ponto; ele náo existiria senão no comum sensorium; ele teria apenas uma única ideia, aquela do eu à qual associaria todas suas sensaçôes. (OC IV, p.280).

Tal como a estátua de Condillac, o homem-criança de Rousseau é definido somente por aquilo que recebe pelos sentidos, ele náo é outra coisa, senão aquilo que sente. Podemos perceber melhor essa aproximação, ao lermos a seguinte passagem do Tratado das Sensaçôes, em que Condillac (1984, p. 87) se refere a sua estátua:

Ela não supõe então que ela deva suas maneiras de ser às causas exteriores; ela ignora que estas lhe vêm pelos quatro sentidos ${ }^{9}$. Ela vê, ela sente o odor, ela degusta, ela escuta, sem saber que ela tem olhos, um nariz, uma boca, orelhas: ela não sabe que possui um corpo. [...] é na maneira de ser em que ela se encontra sempre, que ela deve sentir esse eu que lhe parece o sujeito de todas as modificações da qual ela está suscetível.

\footnotetext{
${ }^{8}$ Sobre a necessidade de aprender a ver, Condillac cita a seguinte passagem da Philosophie de Newton, de Voltaire: "O objeto próprio e imediato da vista não é outra coisa senão a luz colorida; todo o resto, nós o sentimos apenas com o tempo e pela experiência. Nós aprendemos a ver precisamente como aprendemos a falar e a ler. A diferença é que a arte de ver é mais fácil, e que a natureza é igualmente, para todos, nossa mestra." (VOLTAIRE apud CONDILLAC, 1987, p.453).

${ }^{9}$ Nesse momento, a estátua ainda não possui o tato.
} 
A adesão de Rousseau às teses sensualistas de Condillac prossegue, de sorte que encontramos outras afirmaçóes de Rousseau que parecem ter sido extraídas diretamente do Tratado das Sensaçôes. "As primeiras sensações das crianças são puramente afetivas, elas não percebem senão o prazer e a dor" (OC IV, p.282), defende Rousseau, que segue, quase literalmente, o texto de Condillac: "[...] nossas primeiras ideias não são senão de sofrimento ou prazer" ${ }^{10}$ (CONDILLAC, 1984, p.58). A hierarquia dos sentidos nos dois filósofos é quase a mesma: para Rousseau, o sentido mais importante é o tato e, depois, em ordem decrescente, a visão, a audição, o paladar e o olfato; para Condillac, o tato também é o mais importante e, depois, seguem a visão, o paladar, a audição e o olfato. xxx

Esse destaque atribuído ao tato pode ser encontrado já em Berkeley, que no Essai d'une nouvelle théorie de la vision defende que é através do tato que nós adquirimos as ideias de grandeza, perspectiva, distância e posição, às quais não teríamos acesso através somente da visão. De acordo com Jimack (1960), foi Voltaire quem popularizou tais ideias na França através dos Eléments de la philosophie de Newton. Voltaire, entretanto, vai um pouco mais longe que Berkeley e atribui ao tato a dedução da existência do mundo exterior, "dedução que Condillac aceita no seu Tratado das Sensaçóes. Sem o tato sua estátua não teria consciência do mundo exterior" (JIMACK, 1960, p.331).

Condillac reserva a segunda e a terceira parte do Tratado das Sensaçôes para o estudo do tato, sendo que o terceiro capítulo da última parte é dedicado "à importância do tato para fazer nascer as ideias de extensão, de perspectiva, de forma etc., e, consequentemente, para desenvolver o sentido da visão" (JIMACK, 1960, p.331). A descrição de Rousseau sobre as primeiras impressóes das crianças aproxima-se bastante do pensamento de Condillac a respeito dessa relação do tato com a visão:

Ele quer tocar tudo, manipular tudo; não vos oponha a essa inquietude; ela sugere um aprendizado muito necessário, é assim que ela aprende a sentir o calor, o frio, a dureza, a moleza, o peso, a leveza dos corpos, a julgar suas grandezas, suas figuras e todas as suas qualidades sensíveis olhando, apalpando, escutando, sobretudo comparando a visão ao tato. (OC IV, p.284)

\footnotetext{
${ }^{10}$ Sobre o caráter fundamental desempenhado pelo "par prazer/dor", no sensualismo de Condillac, cf. Monzani (1993).
} 
Rousseau parece resumir o capítulo 3 da terceira parte do Tratado das Sensaçôes quando conclui que "não é senão pelo movimento que nós aprendemos que existem coisas que não são nós, e é somente pelo nosso próprio movimento que adquirimos a ideia de extensão" (OC IV, p.284). Cabe lembrar que tais ideias sobre o tato e a visão são também defendidas por Buffon, que classifica o tato como responsável pela aquisição de "conhecimentos completos e reais, é esse sentido que retifica todos os outros sentidos", os quais nos iludiriam caso "o tato não nos ensinasse a julgar" (BUFFON apud JIMACK, 1960, p.333). Pensamento semelhante ao que encontramos nos primeiros livros do Emílio, em que, como observa Jørn Schøsler (1978), Rousseau realiza um detalhado estudo dos sentidos que visa "observar quais são os conhecimentos particulares de cada um deles, atribuindo somente ao tato a função essencial de fazer a criança descobrir a existência do mundo exterior e de corrigir, por causa de seu contato mais seguro com o mundo, as impressóes dos outros sentidos"11 (SCHØSLER, 1978, p. 64).

Sobre essa característica do pensamento de Rousseau, Jimack conclui que, embora o autor do Emilio contradiga a identidade entre 'sentir' e 'julgar', defendida por Helvétius, a concepção rousseauniana de "ideia e de pensamento permanece profundamente sensualista” ${ }^{12}$ (1960, p. 326). Por fim, o comentador afirma que:

Se, comparado a Helvétius, Rousseau tem tendência cartesiana, comparado aos Cartesianos puros, ele é certamente sensualista, tanto pela sua concepção da razão como pela sua teoria das ideias. [...] Se, [...] pelo emprego que ele quer fazer da razão ele é cartesiano, sua concepção da razão, desenvolvida e fundada sobre os sentidos, nos parece antes de tudo sensualista. [...] Por fim, sobre a gênese das ideias, Rousseau aceita, com algumas diferenças de vocabulário e algumas ligeiras modificaçoes, as análises de Buffon e do Essai de Condillac. (JIMACK, 1960, p.327-8)

\footnotetext{
${ }^{11}$ Sobre a importância do tato na educação do Emílio cf. OC IV, p.388 e ss.

${ }^{12}$ A fim de reforçar o posicionamento sensualista de Rousseau e salientar a importância que as experiências sensoriais possuem na constituição de sua personalidade, valeria lembrar aqui o papel que o genebrino pretendia atribuir ao seu projeto da Moral sensitiva, mencionado nas Confissöes (OC I, p. 408). Segundo Raymond (1962, p. 42), esse projeto visa uma "terapêutica pela qual ele possa corrigir sua natureza organizando ao redor dele um meio favorável, dispondo os objetos de tal forma que eles possam modificar a seu bel-prazer seus estados de sensibilidade”. Se a aguçada sensibilidade de Rousseau lhe representa um perigo, através desse estratagema, que ele denomina também de "Materialismo do sábio", a ameaça transforma-se em algo positivo quando ele oferece a si mesmo, deliberadamente, "impressôes e influências que o transformam no sentido que ele deseja, que o ajudam a realizar o desejo de sua consciência, que regulam de fora o curso de sua vida interior." (RAYMOND, 1962, p. 43). De acordo com o comentador, Rousseau reconhece, assim, a influência permanente da realidade material exterior sobre a vida interior.
} 
Podemos perceber através dos comentários acima, que demonstram o caráter sensualista do pensamento rousseauniano, a proximidade de Rousseau com a filosofia do seu tempo. "Apesar de suas invectives contra os 'philosophes', apesar da Profissão de fé do Vigário saboiano, apesar do estreito parentesco que o une a Plutarco e aos antigos, o autor do Emílio é penetrado do espírito filosófico e sensualista de seu século", conclui Jimack (1960, p.344). Entretanto, conforme já mencionado anteriormente, a adesão de Rousseau ao sensualismo de Condillac encontrará um limite muito claro: a redução de todas as atividades do espírito à sensação, a redução do eu à matéria.

\section{O ANTIMATERIALISMO DO VigÁRIO}

Nas notas escritas no seu exemplar do De l'Espritt ${ }^{13}$, Rousseau começa a elaborar sua crítica ao materialismo exposta na Profissão de fé. Na margem da página nove do livro de Helvétius, Rousseau faz a seguinte anotação: "perceber os objetos é sentir; perceber suas relaçóes é julgar" (OC IV, p.1122). E conclui em outra anotação ainda na mesma página: "Uma coisa é sentir uma diferença entre uma toesa e um pé; outra coisa é medir essa diferença. Na primeira operação o espírito é puramente passivo, mas na outra ele é ativo" (OC IV, p.1123). Na Profissão de fé, o Vigário saboiano retoma tais argumentos quase nos mesmos termos e aprimora sua crítica ao materialismo dominante de seu século:

Perceber é sentir; comparar é julgar; julgar e sentir não são a mesma coisa. Pela sensaçáo, os objetos se oferecem a mim separadamente, isolados, tais como eles estão na natureza; pela comparação, eu os transporto, por assim dizer, eu os ponho um sobre o outro para pronunciar sobre suas diferenças ou sobre suas semelhanças, e geralmente sobre todas as suas relaçóes. A meu ver, a faculdade distintiva do ser ativo ou inteligente é poder dar um sentido a palavra é. Eu procuro em vão no ser puramente sensitivo essa força inteligente que sobrepóe e que depois pronuncia. (OC IV, p.571).

Logo após concluir, sem dificuldades, sobre a existência material do mundo exterior ${ }^{14}$ - o que resulta numa completa indiferença em relação às "disputas dos idealistas e materialistas" sobre a "aparência e a realidade dos corpos" -, o Vigário defende então a força ativa do espírito no ato de comparar os diferentes objetos oferecidos pelas sensaçóes, o que configura um

\footnotetext{
${ }^{13}$ Tais notas foram publicadas no tomo IV das Oeuvres Complètes de Rousseau (ed. Pleiade).

14 "Eu concebo entâo claramente que minha sensação, que está em mim, e sua causa ou seu objeto, que está fora de mim, não são a mesma coisa.” (OC IV, p. 571).
} 
verdadeiro dualismo no conhecimento humano entre atividade do julgamento e passividade das sensaçóes. Dualismo evidenciado, por exemplo, quando o padre defende que as "ideias comparativas, maior, menor, assim como as ideias numéricas de um, de dois, etc. certamente não são sensaçôes, embora meu espírito só as produza por ocasião de minhas sensaçóes." (OC IV, p. 572). $\mathrm{O}$ aspecto singular do papel ativo do espírito consiste nessa capacidade de atribuir qualidades às coisas, ou seja, "dar um sentido à palavra $e$ ".

$\mathrm{O}$ Vigário percebe que ele não possui o "poder de sentir ou de não sentir", pois as sensaçôes lhe são impostas pelo mundo exterior. Entretanto, seu espírito ativo pode examinar aquilo que ele sente, e é exatamente nessa atividade que se pode encontrar a origem do erro: "Sei apenas que a verdade está nas coisas e não no meu espírito que as julga, e que, quanto menos coloco de meu nos juízos que faço sobre elas, mais estou seguro de me aproximar da verdade. Assim, minha regra de me entregar mais ao sentimento do que à razão é confirmada pela própria razão.” (OC IV, p. 573). É importante frisar que o Vigário deposita essa confiança não somente nas "sensações", mas no "sentimento", ou seja, no "bom senso natural", como sugere Burgelin (1969, p. 1524) - distinção que o permite observar nessa passagem um deslizamento “do 'sensitivo', que é passividade, ao 'sentimento' que implica já certa atividade do eu." (BURGELIN, 1969, p. 1524). Tal interpretação poderia torna-se um pouco complicada quando o Vigário retoma o mesmo raciocínio mais adiante e afirma: "porque a operação que compara é falível, e meu entendimento, que julga as relaçóes, mistura seus erros à verdade das sensaçóes, que só mostram objetos."15 (OC IV, p. 573). Nessa passagem, o padre opóe os enganos do entendimento às verdades das sensaçôes, não ao sentimento. Entretanto, ele observa que o uso da força ativa do espírito, mesmo que mínimo, é necessário para que tenhamos qualquer acesso à realidade do mundo exterior, pois:

Se fôssemos meramente passivos no emprego de nossos sentidos, não haveria entre eles nenhuma comunicação; ser-nos-ia impossível saber que o corpo que tocamos e o objeto que vemos são o mesmo. Ou jamais sentiríamos nada fora de nós, ou haveria para nós cinco substâncias sensíveis, cuja identidade nunca poderíamos notar. (OC IV, p. 573).

\footnotetext{
${ }^{15}$ Gouhier (2005) observa que Rousseau recorre à mesma explicação sobre a origem do erro exposta por Descartes no artigo 33 de Les Principes de la Philosophie, onde podemos ler a seguinte afirmação: "quando nós percebemos qualquer coisa, nós não estamos em perigo de nos enganarmos se nós não julgarmos de nenhuma forma”.
} 
O homem, assim definido pelo Vigário, é sensivel e passivo, mas também ativo e inteligente. Atividade que the possibilita igualmente a liberdade de suas ações e lhe assegura, portanto, sua espiritualidade, afinal, a liberdade não poderia derivar da substância material. Isso é o que define o terceiro artigo de fé: "o homem é então livre em suas ações e como tal, animado de uma substância imaterial" (OC IV, p. 586). Rousseau retoma aqui o tema abordado no Discurso sobre a desigualdade que diferencia o homem dos animais a partir exatamente do reconhecimento da liberdade que lhe possibilita escapar, ou resistir, às determinaçóes da natureza.

A defesa da espiritualidade do eu encontra seu fundamento na "consciência dessa liberdade", pois é nela "que se mostra a espiritualidade de sua alma" (OC III, p. 142). Se a "física explica de alguma forma o mecanismo dos sentidos e a formação das ideias" (OC III, p. 142) nos animais, tal tipo de explicação é impossível para o homem, pois, "na potência de querer, ou antes, de escolher, e no sentimento dessa potência não se encontram senão atos puramente espirituais dos quais não se explica nada pelas Leis da Mecânica.” (OC III, p. 142).

Preocupado com as consequências morais de sua filosofia do conhecimento, Rousseau se volta para o "eu que toma decisóes e que se inquieta com seu livre arbítrio" (GOUHIER, 2005, p. 69). Sua investigação se dirige, assim, para o problema da origem do julgamento: "que direito eu tenho de julgar as coisas e o que é que determina meus julgamentos?" ( $O C$ IV, p. 570), questiona-se o Vigário. Enquanto para Condillac o julgamento "não é senão a percepção de uma relação entre duas ideias, que comparamos"16 (CONDILLAC, 1984, p. 22), para o autor da Profissáo de fé, o julgamento é resultado da intervenção ativa do $e$, posicionado fora das sensaçóes, que possui em si a "faculdade de comparar" os objetos exteriores.

Sobre uma possível origem dessa concepção ativista de Rousseau, Schøsler afirma que podemos encontrá-la na mesma fonte da qual Condillac derivou as conclusóes extremas do seu sensualismo. Trata-se do Ensaio acerca do entendimento bumano, de Locke. De acordo com Schøsler, enquanto Condillac leva mais longe o empirismo do filósofo inglês e procura mostrar que "as operaçóes intelectuais do espírito não são, como supôe Locke, faculdades inatas, mas hábitos mentais, redutíveis à sensação” (1978, p. 64), Rousseau, por outro lado, recorre ao empirismo mais moderado de Locke a fim de se contrapor à conclusáo radical de Condillac. $\mathrm{O}$ autor do Emílio retoma assim

16 "Nossa estátua náo pode ser ao mesmo tempo atenta ao odor da rosa e ao de dianthus (oeillet) sem perceber que uma não é outra.” (CONDILLAC, 1984, p. 22) 
a posição ativista de Locke, para o qual a passividade do espírito consiste na recepção, pelos sentidos, das ideias simples ${ }^{17}$ (que Rousseau denomina sensaçóes simples), mas alega que o espírito permanece ativo na medida em que ele tem o "poder de reproduzi-las, de compará-las, de uni-las em conjunto, com uma variedade quase infinita e de formar, por esse meio, novas ideias complexas, de acordo com o que ele acha conveniente" (LOCKE, 1975, p. 119). Essa atividade do espírito para a formação das ideias complexas é, segundo Schøsler, fortemente retomada, reformulada e defendida por Rousseau, na Profissáo de $f e ́$, contra o posicionamento extremo do sensualismo de Helvétius e Condillac.

Gouhier, diferentemente de Schøsler, vê no "ativismo" de Rousseau um retorno, não ao empirismo de Locke, mas ao "esquema cartesiano que define o julgamento distinguindo um entendimento que percebe e uma vontade que dá o assentimento" (GOUHIER, 2005, p. 71). Para se opor ao materialismo, segundo o comentador, Rousseau deixa de lado o Tratado das sensaçóes e parece abrir Les Principes de la Philosophie, em que Descartes expóe no artigo 32 a distinção entre entendimento e vontade nos seguintes termos:

todas as formas de pensar que constatamos em nós podem ser atribuídas à duas gerais, das quais uma consiste em perceber pelo entendimento e a outra em se determinar pela vontade. Assim, sentir, imaginar, e mesmo conceber coisas puramente inteligíveis, não são senão formas diferentes de perceber; mas desejar, ter aversão, assegurar, negar, duvidar, são formas diferentes de querer. (DESCARTES, 1989, p. 76)

Mesmo que Rousseau defina entendimento como "o poder de comparar e julgar” (OC IV, p. 586), o que, para Descartes, seria a vontade, pode-se perceber um paralelo na definição de julgamento para os dois filósofos, na medida em que ambos concordariam que, "afirmar ou negar uma relação é outra coisa que ver os termos dessa relação; aqui e lá, existe a oposição entre o que é ativo e o que é passivo" (GOUHIER, 2005, p. 71).

Qualquer que seja nosso posicionamento diante da divergência exposta acima sobre a possível origem filosófica do ativismo de Rousseau - proveniente do empirismo moderado de Locke, para Schøsler, ou retomado da distinção

\footnotetext{
${ }^{17}$ No Ensaio sobre o entendimento humano, livro II, $\$ 25$, Locke descreve a passividade do espírito na origem das ideias simples: "Na recepção das ideias simples, o entendimento é, na maior parte, passivo. [...] Essas ideias simples, quando oferecidas à mente, o Entendimento não pode mais se recusar a ter, nem alterar, quando são impressas [...]. Assim como os Corpos que nos rodeiam afetam diversamente nossos Órgãos, a mente é forçada a receber as impressōes; e não pode evitar a percepção daquelas Ideias que estão anexadas a elas" (LOCKE, 1975, p. 118).
} 
cartesiana entre o entendimento e a vontade -, não há como discordar quanto à dificuldade de enquadrar o pensamento do genebrino numa determinada tradição filosófica. Podemos até supor que ele esteja anunciando a tarefa kantiana de "conciliar" empiristas e racionalistas, mas não pretendemos investigar aqui tal possibilidade.

\section{A CAUSA Do movimento}

A relação entre o sensualismo e o antimaterialismo de Rousseau torna-se relevante quando o Vigário realiza sua reflexão sobre a origem do movimento; reflexão que se origina quando o padre dirige seus olhos para o universo:

Tendo-me, por assim dizer, assegurado de mim mesmo, começo a olhar para fora de mim, e considero-me com uma espécie de frêmito, jogado, perdido neste vasto universo e como que afogado na imensidáo dos seres, sem nada saber sobre o que eles são, nem entre eles, nem relativamente a mim. Estudo-os e observo-os, e o primeiro objeto que se apresenta a mim para compará-los sou eu mesmo.

Tudo que percebo pelos sentidos é matéria, e deduzo todas as propriedades essenciais da matéria das qualidades sensíveis que me fazem percebê-la e que são inseparáveis dela. (OC IV, p. 573).

Mesmo que a experiência daquele que se depara com a vastidão do universo cause algum frémissement, quiçá prazeroso, ao perceber aí a presença divina, por outro lado, a ausência de qualquer explicação razoável sobre o funcionamento do universo lhe desperta uma inquietação que requer algumas respostas para ser superada. Daí a necessidade de "estudar" e "observar" o mundo. Estudo este conduzido pela interaçáo entre a passividade das sensaçóes e a atividade do espírito, que compara e julga.

Dado que a experiência sensorial lhe permite deduzir "as propriedades essenciais da matéria”, quando o Vigário dirige sua atenção para o problema do movimento, o que ele vê são corpos tanto em movimento como em repouso, o que evidencia que "nem o repouso, nem o movimento lhe são essenciais." $(O C \mathrm{IV}$, p. 574). Deriva, dessa observação, outra conclusão que se refere à necessidade de uma causa para o movimento, enquanto o repouso seria a ausência desta causa - ideia que reproduz o princípio de inércia. 
Para o Vigário, existem dois tipos de movimento: o comunicado e o espontâneo. Enquanto o primeiro possui uma causa exterior, o segundo encontra sua causa no próprio corpo em movimento. O exemplo evocado pelo Vigário para demonstrar a existência do movimento espontâneo é o de seu próprio corpo: "Quero mexer meu braço e mexo-o, sem que esse movimento tenha outra causa imediata além de minha vontade" (OC IV, p. 574). Algo bastante significativo nessa passagem diz respeito à forma como o Vigário aquiesce à veracidade desse exemplo. Consentimento que provém do fato de ele sentir isso ocorrer em si mesmo; e tal sentimento "é mais forte do que qualquer outra evidência." (OC IV, p. 574). O Vigário não se refere aqui à experiência sensorial que percebe o movimento, mas ao sentimento interior que impossibilita a razão de discordar dessa evidência.

O mesmo sentimento interior, que atribui a causa do movimento do corpo humano à vontade, é incapaz de aceitar "a ideia da matéria não organizada movendo-se por si mesma.” (OC IV, p. 575). Esse é um ponto extremamente importante no combate ao materialismo, pois se refere à recusa de que a matéria pode ser a causa de seu próprio movimento. Para o Vigário, um corpo em movimento só pode ser um corpo animado ou um corpo que sofreu uma comunicaçáo de movimento, ou seja, um corpo desprovido de alma jamais é a causa do seu próprio movimento.

Somente uma vontade pode ser a causa primeira do movimento, é isso que o Vigário experimenta nele mesmo, "eu quero mover meu corpo, e meu corpo se move” (OC IV, p. 576), esse é o único modelo que ele dispóe para explicar a origem do movimento. A mesma oposição encontrada entre a passividade das sensaçóes e a atividade do espírito é retomada aqui em outros termos, trata-se agora da passividade da matéria e da atividade da vontade.

Se a matéria é passiva, para o Vigário, isso se deve ao fato de esta ser definida como "matéria morta" (OC IV, p. 575). Ora, o que os materialistas do século XVIII procuram realizar é exatamente o oposto, ou seja, a "vitalização" da matéria, e é essa concepção que lhes possibilita defender a causa do movimento como inerente à matéria. "Nada está em repouso absoluto", afirma Diderot nos Principes philosophiques sur la matière et le mouvement (2010b, p. 447), e completa mais adiante: "o repouso absoluto é um conceito abstrato que não existe na natureza, e o movimento é uma qualidade tão real quanto o comprimento, a largura e a profundeza" (2010b, p. 448). Pensamento semelhante sobre a origem do movimento é encontrado também em La Mettrie. Em L'Homme-machine, publicado em 1748 , ele defende que a matéria pode se mover por si mesma. 
Segundo La Mettrie, mesmo que nos seja impossível conhecer a natureza do movimento, assim como a da matéria - "estou tâo consolado de ignorar como a matéria, de inerte e simples se torna ativa e composta de órgãos, quanto de não poder olhar o sol sem lente vermelha" (LA METTRIE, 2004, p. 78) -, é possível consentir, entretanto, "que a matéria organizada é dotada de um princípio motor, [...] e que tudo depende nos animais da diversidade dessa organização." (LA METTRIE, 2004, p. 78).

Para o Vigário, ao contrário, a ausência de qualquer princípio motor na matéria lhe garante que "o mundo não é um grande animal que se move por si mesmo.” (OC IV, p. 575). A atividade, a fonte do movimento, é um atributo do espírito, como ele defende ao constatar, contra Helvétius, que o julgamento é uma atividade do espírito que não pode ser reduzida a um conjunto de sensaçóes. O único princípio ativo que o padre saboiano conhece é a vontade. Logo, o primeiro motor não pode ser outro:

As primeiras causas do movimento não estão na matéria; ela recebe o movimento e comunica-o, mas não o produz. Quanto mais observo a ação e a reação das forças da natureza agindo umas sobre as outras, mais acho que, de efeitos em efeitos, devemos sempre remontar a alguma vontade como primeira causa; pois supor um progresso de causas ao infinito é não supor causa nenhuma. Em uma palavra, todo movimento que náo é produzido por outro, não pode vir senáo de um ato espontâneo, voluntário; os corpos inanimados não agem senão pelo movimento, e não existe verdadeira ação sem vontade. Eis o meu primeiro princípio. Creio, portanto, que uma vontade move o universo e ainda a natureza. Eis o meu primeiro dogma, ou o meu primeiro artigo de fé. (OC IV, p. 576).

O problema suscitado pelo fato inexplicável de como a atividade espiritual pode produzir uma ação física não representa para o Vigário uma dificuldade intransponível, pelo contrário, a própria experiência individual lhe demonstra a veracidade do dualismo: "eu experimento em mim que ela a produz. [...] eu quero mover meu corpo, e meu corpo se move" (OC IV, p. 576). Por outro lado, "é incompreensível e sem exemplo" imaginar que um corpo inanimado possa se movimentar por si mesmo. Contra os ataques dos materialistas, o padre saboiano defende o dualismo argumentando que "um movimento produzido pela vontade, sentida como causa, é menos incompreensível do que um movimento produzido pela matéria." (BURGELIN, 1969, p. 1528). O Vigário não ignora a obscuridade do seu primeiro dogma, entretanto, "ele oferece um sentido e não tem nada que 
repugne à razão, nem à observação" (OC IV, p. 576-7), enquanto o mesmo não pode ser dito acerca do materialismo.

O estabelecimento do primeiro artigo de fé representa, assim, a conclusão inicial obtida através do olhar que se volta para si mesmo e para o universo, para a physis. Olhar que pode ser compreendido num sentido mais amplo que a experiência sensorial, abrangendo igualmente o sentimento despertado no sujeito. Quando o Vigário realiza essa tarefa investigativa sobre si mesmo e sobre a natureza, uma das verdades fundamentais que ele encontra, mesmo que seja na forma de um dogma, concerne à origem voluntária do movimento como única causa possível, o que termina por estabelecer uma íntima relaçấo entre aquilo que ocorre no universo e o que ocorre no homem.

No processo de busca pelas respostas sobre aquilo que "realmente importa", o padre realiza agora um passo consideravelmente importante. $\mathrm{O}$ consentimento da existência do princípio ativo - tanto na origem do movimento quanto no pensamento - permite ao Vigário, desde então, oporse radicalmente à hipótese levantada por Locke no Ensaio sobre o entendimento humano (livro IV, cap. III, $\$$ 6) sobre a possibilidade de a matéria pensar; hipótese que poderia ser considerada como ponto de partida para o materialismo setecentista ${ }^{18}$. Nas palavras do filósofo inglês:

Nós temos ideias de Matéria e de Pensamento; mas talvez nós nunca sejamos capazes de conhecer se um ser puramente material pensa ou não: pela razão que nos é impossível descobrir, pela contemplaçáo de nossas próprias ideias, sem Revelação, se a Onipotência não deu a algum Sistema de Matéria adequadamente disposto o poder para perceber e pensar, ou se adicionou e uniu à Matéria assim disposta uma Substância imaterial que pensa. Assim sendo com respeito a nossas noçóes, nấo muito mais remotas para compreender que Deus pode conceber, se lhe apraz, e acrescentar à Matéria a Faculdade de Pensar, do que ele poderia acrescentar outra substância com a Faculdade de Pensar. Eu não vejo nenhuma contradição nisso, que o eterno Ser pensante possa, se lhe apraz, dar para certo Sistema de matéria criado e insensível [...] algum grau de sentido, percepção e pensamento. (LOCKE, 1975, p. 540-1).

\footnotetext{
${ }^{18}$ Antes de continuar a análise sobre a contraposição do Vigário às conclusões materialistas acerca do movimento, seria de considerável importância realizar alguns breves comentários sobre o florescimento do materialismo biológico no século das Luzes, a fim de esclarecer, mesmo que sumariamente, a formação e fundamentação das ideias que serão tão fortemente atacadas por Rousseau.
} 
Na décima terceira das Cartas filosóficas, intitulada "Sobre Locke", Voltaire defende a coerência de tal questionamento, o que garantiu uma grande divulgação dessa passagem do texto de Locke que, por sua vez, parece não ter a intenção de aceitar a ideia de que a matéria possa ter sentimento e pensamento. Entretanto, como aponta Gouhier (2005, p. 76), "quaisquer que tenham sido as intençóes do autor do Ensaio sobre o entendimento humano, a suspeita lançada sobre o dualismo da res cogitans e da res extensa abria o caminho para o materialismo biológico de Maupertuis, de Diderot, de Helvétius”.

Dentre as defesas do materialismo biológico no Iluminismo, destaca-se o esforço de Diderot em mostrar a importância da biologia no processo de abertura de novos horizontes para o conhecimento científico. Em 1754, em De linterpretation de la nature, o enciclopedista consegue resumir de maneira bastante eficaz o movimento que ocorria no século XVIII de deslocamento da matemática para a biologia como ciência modelo. As grandes transformaçóes científicas, as novas descobertas realizadas a partir da experimentação e da observação rigorosa da natureza são notadas por Diderot, que arrisca anunciar o esgotamento de novas descobertas no domínio da geometria, a qual, segundo o filósofo, "no essencial, permanecerá no estado em que a conduziram os Euler e os Bernouilli, os D’Alembert e os Lagrange” (2010a, p. 287). Cassirer (1966, p. 123) lembra que não haviam passado ainda cem anos quando "morreu Gauss, que havia renovado mais uma vez toda a estrutura das matemáticas". Diderot, entretanto, acerta quando constata que:

as matemáticas não podem mais, a partir de entáo, pretender o monopólio da autoridade no domínio das ciências da natureza. (...) Elas [as matemáticas] não podem, com efeito, escapar ao círculo de seus próprios conceitos, elaborados por elas mesmas, elas são desprovidas de todo acesso direto à realidade empírica, concreta das coisas. Somente a experimentaçáo, a observação fiel da natureza pode nos abrir esse acesso. (CASSIRER, 1966, p. 124).

O editor da Enciclopédia procura defender que, através do desenvolvimento do método experimental, as ciências da natureza deverão se tornar independentes em relaçáo tanto aos sistemas metafísicos quanto às matemáticas. Era necessário, para isso, recuperar o atraso do conhecimento no domínio da natureza quanto ao saber matemático, o qual já se encontrava suficientemente desenvolvido. "As ciências abstratas há muito tempo ocuparam os melhores espíritos com poucos resultados; ou não se estudou 
o que importava saber”, afirma Diderot (2010a, p. 294). As matemáticas são "uma espécie de metafísica geral em que os corpos são destituídos de suas qualidades individuais" (DIDEROT, 2010a, p. 286). Por outro lado, os estudos da natureza realizados no século XVIII ultrapassam os esquemas abstratos dos geômetras, eles descobrem na matéria, como o faz Maupertuis no Systeme de la Nature, "não somente as características de extensão, impenetrabilidade, de gravidade etc., mas também aquelas do desejo, da aversão e da memória." (CASSIRER, 1966, p. 139).

O problema da substância imaterial no dualismo cartesiano, "que difere essencialmente da matéria e que a ela está unida” (DIDEROT, 1990, p. 257), é superado pelo materialismo, pois este atribui à matéria qualidades que, para Descartes, pertenciam à alma. Na filosofia materialista de Maupertuis, à qual Diderot faz eco em De l'interprétation de la nature, a vida espiritual surge a partir da agregação de átomos, sendo que a cada uma dessas partes “é atribuído não somente um 'instinto' que a conduz a procurar o que lhe convém e a fugir do que lhe é contrário, mas igualmente um sentimento dela mesma" que, quando os átomos se associam, faz surgir "uma nova consciência comum." (CASSIRER, 1966, p. 140). Dessa forma, ao rejeitar o conceito de substância imaterial, Diderot infere que a sensibilidade é "uma qualidade geral e essencial da matéria" e, para o espanto de Rousseau, conclui que "a pedra sente" (DIDEROT, 1990, p. 258).

Ao atribuir tais qualidades à matéria, Diderot e os philosophes que recusam o dualismo cartesiano reabilitam "velhas intuiçóes monistas que vitalizam a matéria" (GOUHIER, 2005, p. 76). A filosofia materialista do século XVIII reintroduz, assim, "o psíquico no físico, não, certamente, para espiritualizar a matéria, mas para materializar o espírito” (GOUHIER, 2005, p. 79). É precisamente esse pensamento que o Vigário visa combater quando chama de "sofista de má fé" o filósofo que diz que "as árvores sentem e os rochedos pensam.” (OC IV, p. 585).

A Profissão de fé do Vigário saboiano procura combater, assim, a retomada de velhas noçóes, como a de "almas sensitivas", que indicam "a presença na matéria de faculdades análogas ao desejo, à memória, à percepção, à inteligência” (GOUHIER, 2005, p. 79). Assim como Descartes, que opôs sua física matemática ao pensamento renascentista, Rousseau reage contra o que Gouhier chama de prolongamento da Renascença no século XVIII. $\mathrm{O}$ autor do Emílio recusa-se a "levar a sério as cosmogonias onde renascem platonismo, epicurismo e estoicismo.” (GOUHIER, 2005, p. 78). 
Essa interpretação de Gouhier, a respeito da Profissão de fé, o faz concluir que a importância histórica do texto de Rousseau consiste no fato de, ao se opor à filosofia materialista dominante no século XVIII, o genebrino retoma alguns dos principais conceitos da filosofia cartesiana: a distinção das duas substâncias e a indiferença da matéria em relação ao movimento: "eu a vejo tanto em movimento quanto em repouso, de onde eu infiro que nem o repouso nem o movimento lhe são essenciais.” (OC IV, p. 573-4). Gouhier aponta que tal concepção a respeito do movimento foi, muito provavelmente, extraída da segunda parte dos Principes de la Philosophie, mais precisamente dos artigos 27,36 e $37^{19}$.

Outra referência praticamente direta do Vigário a Descartes pode ser encontrada na própria definiçáo de movimento, posta nos seguintes termos: "a ideia de movimento não é outra coisa senão a ideia do transporte de um lugar a outro" (OC IV, p. 577). No artigo 25 da segunda parte dos Principes de la philosophie, Descartes afirma que o movimento "é o transporte de uma parte da matéria ou de um corpo da proximidade daqueles que o tocam imediatamente, e que consideramos em repouso, para a proximidade de alguns outros." (DESCARTES apud GOUHIER, 2005, p. 80). Essa definição opunha-se frontalmente ao aristotelismo, assim como às concepçóes animistas da matéria, na medida em que a fonte do movimento é necessariamente exterior ao corpo movido. Rousseau, por sua vez, realiza o mesmo embate com os philosophes, tendo em vista que:

o materialismo biológico reintroduz a noçáo de forças ocultas que agem por impulsão à maneira do desejo e da aversão; ele pretende encontrar a garantia da ciência na atração newtoniana, para remeter, "naquele que move", a fonte do movimento; é assim que ele encontra a velha imagem: "o mundo, semelhante a um grande animal, tem uma alma”. Ora, o Vigário recusa a imagem precisamente renovando o gesto cartesiano que expulsa da coisa movida a causa do movimento. [...] Assim, a teodiceia de Rousseau apoia suas demonstraçóes sobre as teses fundamentais do mecanicismo cartesiano, a inércia natural da matéria da qual a essência é ser extensa, a reduçấo de todos seus movimentos ao transporte de um lugar ao outro. (GOUHIER, 2005, p. 81)

\footnotetext{
${ }^{19}$ No artigo 27, Descartes afirma que "o movimento e o repouso são apenas dois modos diversos nos corpos onde eles se encontram"; no artigo 36 lemos que "Deus é a primeira causa do movimento"; já o artigo 37 "exclui da matéria toda tendência ao repouso e ao movimento." (GOUHIER, 2005, p. 80).
} 
Os comentários de Gouhier apresentados acima sugerem, portanto, que o antimaterialismo do Vigário saboiano retoma alguns argumentos cartesianos a fim de defender tanto a existência da substância imaterial, quanto a completa passividade da res extensa. Por se tratar de uma análise bem documentada, que aponta precisamente quais são as referências cartesianas no texto de Rousseau, podemos sugerir que a clássica leitura que Gouhier faz da Profissáo de fé nos permite, ao menos, compreender um pouco mais a respeito da visão de mundo que o genebrino procura expressar através do Vigário saboiano. Deve-se ressaltar, entretanto, que o texto de Gouhier - Ce que le Vicaire doit à Descartes $^{20}$ - dedica-se, principalmente, a expor a adesão de Rousseau a certas ideias cartesianas, o que demonstra seu caráter parcial.

De todo modo, ao se ter em vista o antimaterialismo de Rousseau, é fundamental que se compreenda que a origem de tal posicionamento encontrase na constatação de que, se aceitamos que a causa dos julgamentos está na matéria, isso implicaria, para o autor do Emílio, num verdadeiro desastre moral, pois não existiria nada exterior à matéria que pudesse ser apontado como responsável pela ação, assim como pela existência do mal.

A incompatibilidade com o pensamento dos philosophes materialistas desperta em Rousseau a necessidade de apresentar filosoficamente sua própria visão de mundo, a qual ele acredita estar de acordo com a ordem da natureza e representaria, portanto, a verdade.

Para o genebrino, as verdades que ele procura expressar através da Profissão de fé representam uma forma bem ordenada de compreender sua existência no mundo, o que lhe seria fundamental para desfrutar de uma vida que não fosse constantemente abalada pelas ideias que o afastam de suas convicçóes no princípio metafísico e divino da moral.

BEZERRA, Gustavo Cunha. Sensualism and anti-materialism in Rousseau. Trans/form/ ação, Marília, v. 39, n. 3, p.39-58, Jul./Set., 2016.

\begin{abstract}
This article analyzes the double movement of Rousseau's thought, which if on one side is sharply sensualist, especially in the first books of Emile, on the other hand finds the limit of that sensualism in the extreme consequences of the materialistic thought of Diderot and Helvetius. We point out the proximity of Rousseau with the thought that comes from the hypothetical statute of Condillac, but at the same time Rousseau's complete rejection of the assertion that "to judge is to feel", proclaimed by Helvetius. To the author of the Profession of Faith of the Savoyard Vicar, judgment
\end{abstract}

${ }^{20}$ Esse texto constitui o segundo capítulo do livro Les Méditations Métaphysiques de Jean-Jacques Rousseau. 
cannot be reduced to passivity of sensation, it is the result of active intervention of the $I$, a free and intelligent will that cannot be confused with the sensations.

KEYWORDS: materialism, Rousseau, sensualism

\section{REFERÊNCIAS}

BURGELIN, P. Notes et variantes (Émile ou De l'éducation). In: ROUSSEAU, J.-J. Oeuvres complètes. Paris: Gallimard, 1969. (Bibliothèque de la Pléiade, Tome IV).

- La philosophie de l'existence de Jean-Jacques Rousseau. 2e éd. Paris: Librairie Philosophique J. Vrin, 1973.

CASSIRER, E. La philosophie des Lumières. Paris: Fayard, 1966.

CHARRAK, A. Présentation et notes. In: ROUSSEAU, J.-J., Emile ou de l'éducation. Paris: GF-Flammarion, 2009.

CONDILLAC, E. B. Traité des sensations. Paris: Fayard, 1984.

. Traité des animaux. Paris: Librairie Philosophique J. Vrin, 1987.

- Tratado das sensaçôes. Tradução Denise Bottman. Campinas, SP: Editora da UNICAMP, 1993.

DESCARTES, R. Les principes de la philosophie: première partie. Paris: Librairie Philosophique J. Vrin, 1989.

DIDEROT. Entretien entre d'Alembert et Diderot. In : Oeuvres philosophiques de Diderot. Paris: Garnier, 1990.

. Pensées sur l'interpretation de la nature. In: DIDEROT. Oeuvres philosophiques. Paris : Gallimard, 2010a. (Bibliothèque de la Pléiade)

. Principes philosophiques sur la matière et le mouvement. In: DIDEROT. Oeuvres philosophiques. Paris : Gallimard, 2010b. (Bibliothèque de la Pléiade).

GOUHIER, H. Les méditations méthaphysiques de Jean-Jacques Rousseau. Paris: Librairie Philosophique J. Vrin, 2005.

HELVÉTIUS, C.-A. De l'esprit. Paris: Fayard, 1988.

JIMMACK, P. D. La genèse et la rédaction de l'Emile de J.-J. Rousseau. Genève: Institut et musée Voltaire, 1960. (Studies on Voltaire and the Eighteenth Century, v. 13).

LA METTRIE, J. O. L'homme machine. In : . Oeuvres philosophiques. Paris: Coda, 2004. p. 9-80.

LOCKE, J. An essay concerning human understanding. Oxford : Oxford University Press, 1975. 
MASSON, P.-M. Édition critique avec une introduction et un commentaire historique. In: La Profession de Foi de Jean-Jacques Rousseau. Paris: Librairie Hachette, 1914.

MONZANI, L. R. O empirismo na radicalidade: introdução à leitura do tratado das sensaçōes. In: CONDILLAC, E. B. Tratado das sensaçôes. Tradução Denise Bottman. Campinas, SP: Editora da UNICAMP, 1993. p. 7-23.

RAYMOND, M. Jean-Jacques Rousseau: la quête de soi et la rêverie. Paris : Librairie José Corti, 1962.

ROUSSEAU, J.-J. Les confessions. In: . Oeuvres complètes. Paris: Gallimard, 1959. p.01-656. (Pléiade, I).

. Discours sur l'origine et les fondements de l'inégalité. In: Oeuvres complètes. Paris: Gallimard, 1964. p.109-223. (Pléiade, III). . Emile. In: . Oeuvres complètes. Paris: Gallimard, 1969. p. 239-868. (Pléiade, IV).

. Lettre à Christophe de Beaumont. In: . Oeuvres complètes. Paris: Gallimard, 1969. p. 927-1007. (Pléiade, IV).

. Notes sur "de l'esprit". In: 1121-1132. (Pléiade, IV).

SCHØSLER, J. La position sensualiste de Jean-Jacques Rousseau. Revue Romane,. Copenhagen: Institut d'Etudes Romanes; Université de Copenhague, v.13, n. 1, 1978. ${ }^{21}$

Recebido em 18/12/2015

Aceito em 23/05/2016 